\title{
Real-Life Effectiveness of Apremilast for the Treatment of Psoriasis in Belgium: Results From the Observational OTELO Study
}

\author{
Pierre-Dominique Ghislain · Jo Lambert • Xuãn-Lan Lam Hoai • \\ Tom Hillary · Pierre-Paul Roquet-Gravy • Michel de la Brassinne • \\ Siegfried Segaert
}

Received: September 17, 2021 / Accepted: October 27, 2021 / Published online: January 3, 2022

(C) The Author(s) 2021

\section{ABSTRACT}

Introduction: Apremilast is approved for the treatment of psoriasis and psoriatic arthritis. However, data on the efficacy and safety of apremilast in clinical practice are limited. We assessed the real-world use and effectiveness of apremilast in patients with moderate to severe plaque psoriasis visiting dermatologist practices

P.-D. Ghislain $(\bowtie)$

Department of Dermatology, University Hospitals

Saint-Luc, Av. Hippocrate 10, 1200 Brussels,

Belgium

e-mail: pierre-dominique.ghislain@uclouvain.be

J. Lambert

Department of Dermatology, Ghent University

Hospital, Ghent, Belgium

X.-L. L. Hoai

Department of Dermatology, University Hospital

Saint-Pierre, Brussels, Belgium

T. Hillary

Department of Dermatology, University Hospital

Leuven, Leuven, Belgium

P.-P. Roquet-Gravy

Department of Dermatology, Grand Hôpital de

Charleroi, Charleroi, Belgium

M. de la Brassinne

Department of Dermatology, CHU de Liège, Liège,

Belgium

S. Segaert

Consultant Dermatologist, Bonheiden, Belgium in Belgium, from the perspectives of the patient and the physician.

Methods: This prospective observational study enrolled adults aged 18 years or more initiating apremilast between 6 April 2017 and 30 June 2018, per Belgian reimbursement criteria. Primary outcome was the Patient Benefit Index for Skin Diseases (PBI-S). Secondary outcomes included the Patient Global Assessment (PtGA), Dermatology Life Quality Index (DLQI), Psoriasis Area and Severity Index (PASI), and body surface area (BSA). Patients were followed up for up to 18 months.

Results: Overall, 122 enrolled patients received at least one dose of apremilast, of which 89 received treatment for more than 150 days and were included in the reference population. Treatment goals most frequently identified (at least $70 \%$ of patients) as "very important" in the PBI-S were related to physical impairments. After 6 months of apremilast treatment, $61-78 \%$ of patients reported they had achieved these goals; only $12.5 \%$ assessed their disease as severe (PtGA, 53.6\% at apremilast initiation) and over half reported a DLQI score of 5 or less, indicating improved quality of life. As assessed by the physician, $68.4 \%$ and $35.1 \%$ of patients achieved at least a $50 \%$ and $75 \%$ reduction in PASI, respectively, at month 6 . Apremilast was well tolerated with no new safety signals identified.

Conclusions: Our real-world data indicate that apremilast fulfils the expectations of Belgian 
patients with moderate to severe psoriasis, and from the perspectives of both the patient and physician, apremilast has a positive impact on their disease.

Trial Registration: ClinicalTrials.gov Identifier NCT03097003.

Keywords: Apremilast; Patient Benefit Index; Patient-reported outcomes; Psoriasis; Quality of life

\section{Key Summary Points}

Why carry out this study?

Data on the real-world effectiveness and tolerability of apremilast for treatment of plaque psoriasis are limited.

This prospective observational study assessed the effectiveness and safety of apremilast for the treatment of moderate to severe psoriasis in Belgian clinical practice, from the perspectives of the patient and the physician.

\section{What was learned from the study?}

Using the Patient Benefit Index for Skin Diseases, patients identified treatment goals relating to physical impairment as most important and the majority of patients achieved these treatment goals following 6 months of apremilast treatment.

Apremilast improved patient-reported outcomes, including quality of life, psoriasis severity and treatment satisfaction, and was well tolerated with no new safety signals identified.

Our real-world data indicate that apremilast fulfils the expectations of Belgian patients with moderate to severe psoriasis, and from the perspectives of both the patient and physician, has a positive impact on their disease.

\section{INTRODUCTION}

Psoriasis is an immune-mediated, progressive, proliferative and potentially debilitating inflammatory disease of the skin. In 2016, the World Health Organization reported that the prevalence of psoriasis worldwide ranges between $0.09 \%$ and $11.43 \%$ with more than 100 million individuals affected, making it a serious global issue [1]. In Europe, psoriasis affects $1-3 \%$ of the general population [1-4]. Plaque psoriasis is the most common type of psoriasis, and almost a third of patients with chronic disease have associated psoriatic arthritis [5]. While there are no validated diagnostic criteria, the clinical manifestation of psoriasis is characterised by sharply demarcated skin lesions that are typically covered with white or silvery scales and can cause itching, stinging and pain. Consequently, the impact of psoriasis on the quality of life (QoL) is significant, with substantial physical, emotional and social burden [6].

The aetiology of psoriasis is not fully understood despite evidence for genetic predisposition [7, 8]. Notably, the role of the immune system has received significant research interest in recent years, allowing development of treatments which target specific immunological aspects of the disease. One such treatment is apremilast, an orally administered systemic drug, which is approved in Europe for the treatment of immune-mediated inflammatory conditions: psoriasis, psoriatic arthritis and Behçet disease [9].

In psoriasis, apremilast is approved for the treatment of moderate to severe chronic plaque psoriasis in adult patients (at least 18 years of age) who fail to respond to, or have a contraindication for, or are intolerant to other systemic therapies including cyclosporine, methotrexate, or psoralen and ultraviolet $\mathrm{A}$ (PUVA) light. The recommended dose is $30 \mathrm{mg}$ twice daily following an initial up-titration phase of 5 days administered orally, independent of meals [10]. 
The efficacy and safety of apremilast in treating patients with psoriasis was demonstrated in the phase III ESTEEM clinical trials $[11,12]$. However, data on the use of apremilast in clinical practice are limited. The OTELO study was designed to describe the real-world use of apremilast for the treatment of moderate to severe plaque psoriasis in patients visiting dermatologist practices in Belgium, and to assess treatment effectiveness from the perspectives of both the patient and treating dermatologist.

\section{METHODS}

\section{Patients}

The OTELO study (NCT03097003) included patients aged 18 years or older, diagnosed with moderate to severe chronic plaque psoriasis (defined by a body surface area [BSA] $>10 \%$ or a Psoriasis Area and Severity Index [PASI] > 10) who had initiated apremilast treatment between 6 April 2017 and 30 June 2018 according to Belgian reimbursement criteria [13]. As per local reimbursement criteria, efficacy was assessed after 6 months; if the patient had achieved a reduction in PASI score of at least 50\% (PASI 50), the treatment could be continued for another 12 months. Otherwise, the treatment was to be interrupted.

Patients allergic to apremilast or its excipients, those treated with apremilast for more than 4 weeks prior to enrolment, pregnant women, breastfeeding women or women not under adequate contraception were excluded. Written informed consent was obtained from all patients before enrolment into the study. The study protocol was approved by the medical ethics committee of UZ Leuven and was conducted in accordance with the International Council for Harmonisation of Technical Requirements for Pharmaceuticals for Human Use Guideline for Good Clinical Practice, the guiding principles of the Declaration of Helsinki and other applicable guidelines for non-interventional studies.

\section{Study Design}

OTELO was a multicentre, prospective, observational study with data collected at routine (3monthly) clinical visits; there were no mandatory study visits. Patient follow-up was between 6 and 18 months (i.e. at 6, 9, 12, 15 and 18 months after apremilast initiation).

\section{Study Objectives and Outcomes}

The primary objective was to assess patient-reported treatment success 6 months after apremilast initiation using the validated Patient Benefit Index for Skin Diseases (PBI-S, standard version). Secondary objectives were to assess the effect of apremilast on patient's QoL using the Dermatology Life Quality Index (DLQI); assess the improvement in disease symptoms from the perspective of the patient, using the Patient Global Assessment (PtGA), and the physician, using the PASI and BSA; and to assess patient treatment satisfaction using the 9-item Treatment Satisfaction Questionnaire for Medication (TSQM-9).

The PBI-S questionnaire evaluates patientdefined benefits of dermatological therapies and consists of two parts [14-16]. The first part, the Patient Needs Questionnaire (PNQ), contains a list of 25 treatment goals and is completed by patients before treatment initiation. A five-step Likert scale $(0=$ "not important at all" to $4=$ "very important") records the relevance of each treatment goal to the patient. In the second part, the Patient Benefit Questionnaire (PBQ), patients evaluate the benefit of their treatment. The PBQ comprises the same items as the PNQ and patients evaluate the extent to which treatment needs have been fulfilled by the treatment (scaled from $0=$ "treatment did not help at all" to $4=$ "treatment helped a lot"). A preference-weighted global benefit score is then calculated for all items of the PNQ and PBQ, which can have a value from $0=$ "no benefit" to 4 = "maximal benefit" $[14,17]$.

The DLQI is a validated questionnaire that measures the QoL across several health dimensions: symptoms and feelings (two items), daily activities (two items), leisure (two items), work 
and school (one item), personal relationships (two items) and treatment (one item). Each item is graded on a Likert scale of 0 to 3 , giving an overall score from 0 to 30 , where lower scores indicate better QoL $[18,19]$.

The TSQM-9 questionnaire is a validated selfadministered questionnaire that comprises nine items evaluating the patient's overall satisfaction with treatment. These nine items make up two specific scales (effectiveness, convenience) and one global satisfaction scale. Scale scores are transformed into scores from 0 to 100 with higher scores representing higher satisfaction in that domain $[20,21]$.

The PtGA asks patients to rate the severity of aspects of their disease on a scale from 0 (clear/ no psoriasis) to 4 (severe) [22, 23].

PASI is a composite score grading the severity of psoriasis in four body regions according to erythema, scaling and thickness as well as the total area of skin affected. The final composite score ranges from 0 to 72 , with a higher score indicating a greater severity of psoriasis $[24,25]$. BSA measures the extent of body coverage by psoriasis [24]. Safety and tolerability of apremilast were assessed using the incidence of treatment-emergent adverse events (TEAEs), defined as adverse events that started or worsened within 6 days before the first dose of apremilast and up to 30 days after the last dose.

\section{Statistical Analysis}

As a result of the observational design of the study, a formal sample size calculation was not performed. Enrolment was planned for approximately 250 patients, which was considered a meaningful cohort relative to the prescribed use of apremilast in Belgium. All analyses were descriptive. The safety analysis set (SAF) included all enrolled patients who had received at least one dose of apremilast and was used to analyse TEAEs. The reference analysis set (REF) included patients receiving at least 150 days of apremilast treatment and was used to analyse all other outcomes. Quantitative variables were described using mean, standard deviation (SD) and 95\% confidence interval (where appropriate). Qualitative variables were presented in terms of absolute frequency and percentage.

Measurements that were not performed or recorded were treated as missing data. For PBI-S, a treatment goal was regarded missing if the patient had not responded to the corresponding item in the PNQ and/or PBQ. If less than $25 \%$ of the treatment goals were missing for an individual, the global PBI score was calculated using the non-missing data. If more than $25 \%$ of the treatment goals were missing for an individual patient, the global PBI score was not calculated. Missing data were excluded from the summary of quantitative and qualitative variables. TEAEs were coded using the Medical Dictionary for Regulatory Activities (MedDRA) version 21.0.

\section{RESULTS}

\section{Patient Characteristics}

Overall, 124 patients were enrolled between 6 April 2017 and 20 December 2018. Of these, 122 had received at least one dose of apremilast and were included in the SAF; 89 had received apremilast for more than 150 days and were included in the REF. Mean (SD) follow-up was 8.7 (4.7) months; 5 (4.1\%) patients had less than 6 months' follow-up (due to termination of the study). At month 6 , over half $(73 / 122$ [59.8\%]) of all patients in the SAF continued with apremilast therapy and one-third (44/122 [36.1\%]) discontinued apremilast (insufficient effectiveness, 26/44 [59.1\%]; TEAEs, 12/44 [27.3\%]; intolerance, $3 / 44$ [6.8\%]); sufficient disease control, $1 / 44$ [2.3\%]; other, 2/44 [4.6\%]).

Patient characteristics are summarised in Table 1. In general, patients included in the SAF and the REF were similar. Mean age was 53-54 years and mean body mass index was $28 \mathrm{~kg} / \mathrm{m}^{2}$. Mean time since initial psoriasis diagnosis was 20 years with scalp psoriasis the most frequent disease manifestation (approximately $70 \%$ of patients), followed by nail psoriasis (39-42\%) and palmoplantar psoriasis (approximately 25\%). In the SAF, the most common comorbidities were hypercholesterolemia $(38 / 122 \quad[31.1 \%]$ patients), 
Table 1 Patient characteristics at apremilast initiation

\begin{tabular}{|c|c|c|}
\hline & $\begin{array}{l}\text { SAF } \\
(N=122)\end{array}$ & $\begin{array}{l}\text { REF } \\
(N=89)\end{array}$ \\
\hline Male, $n(\%)$ & $59(48.4)$ & $43(48.3)$ \\
\hline Female, $n(\%)$ & $63(51.6)$ & $46(51.7)$ \\
\hline $\begin{array}{l}\text { Age at enrolment (years), mean } \\
\text { (SD) }\end{array}$ & $53.1(14.1)$ & $\begin{array}{l}54.1 \\
(14.0)\end{array}$ \\
\hline \multicolumn{3}{|l|}{ BMI, $\mathrm{kg} / \mathrm{m}^{2}$} \\
\hline$n$ & 117 & 87 \\
\hline Mean (SD) & $28.1(5.5)$ & $28.4(5.9)$ \\
\hline $\begin{array}{l}\text { Duration of psoriasis (years), } \\
\text { mean (SD) }\end{array}$ & $19.7(15.6)$ & $\begin{array}{l}20.2 \\
\quad(15.9)\end{array}$ \\
\hline $\begin{array}{l}\text { Patients with scalp psoriasis, } \\
n(\%)\end{array}$ & $88(72.1)$ & $62(69.7)$ \\
\hline $\begin{array}{l}\text { Patients with nail psoriasis, } \\
n(\%)\end{array}$ & $48(39.3)$ & $37(41.6)$ \\
\hline $\begin{array}{l}\text { Patients with palmoplantar } \\
\text { psoriasis, } n(\%)\end{array}$ & $31(25.4)$ & $23(25.8)$ \\
\hline $\begin{array}{l}\text { Number of affected nails, mean } \\
\text { (SD) }\end{array}$ & $9.3(5.3)$ & $10.7(5.0)$ \\
\hline
\end{tabular}

$n$ number of patients with available data or number of patients in the relevant category

$B M I$ body mass index, $R E F$ reference analysis set, $S D$ standard deviation, $S A F$ safety analysis set

cardiovascular disease (31/122 [25.4\%], with the majority suffering from hypertension) and depression (20/122 [16.4\%]).

Most patients (120/122 [98.4\%]) had received at least one prior treatment for psoriasis, most commonly systemic (106/122 [86.8\%]), light (90/122 [73.8\%]) and topical (69/ 122 [56.6\%]) therapies. Few patients $(15 / 122$ [12.3\%]) had received prior biologic therapy. Among patients with prior therapy, most patients were receiving systemics immediately prior to apremilast initiation (74/120 [61.7\%]) and switched to apremilast because of insufficient effectiveness or intolerance $(56 / 120$ [46.7\%; Fig. 1]).

\section{Patient Benefit Index for Skin Diseases}

PBI-S scores are summarised in Fig. 2. The treatment goals most frequently identified in the PNQ as "very important" were related to physical impairments. Regaining control of the disease, being healed from all defects, getting better skin quickly, and being free of itching were identified as "very important" by more than $70 \%$ of patients. Confidence in therapy, finding a clear diagnosis and therapy, leading an everyday normal life, no longer having a burning sensation, and not fearing the disease will become worse were identified as "very important" by more than half of all patients; $47.6 \%$ of patients identified spending less time for daily treatment as "very important". After 6 months of apremilast treatment, more than half of all patients with available data reported a positive response ("very", "quite" or "moderate") in the PBQ regarding achievement of the treatment goals which they had identified as "very important" (Fig. 2). The majority of patients with available data achieved an overall PBI-S $\geq 1$ at months 3 and 6 [83.7\% (36/43) and $92.3 \%(36 / 39)$, respectively], indicating a "minimum clinically relevant benefit" from apremilast.

\section{Dermatology Life Quality Index}

DLQI scores are summarised in Fig. 3. Mean (SD) global DLQI score decreased from 11.2 (6.3) at apremilast initiation to 7.4 (6.2) and 5.8 (5.4) at months 3 and 6, respectively. The percentage of patients with a DLQI score of 5 or less increased from $18.8 \%(16 / 85)$ at apremilast initiation to $49.3 \%(35 / 71)$ and $58.5 \%(38 / 65)$ at months 3 and 6 . Similarly, the percentage of patients with a DLQI score of 0 or 1 increased from $3.5 \%(3 / 85)$ to $16.9 \%(12 / 71)$ and $27.7 \%$ $(18 / 65)$, respectively.

\section{Treatment Satisfaction Questionnaire for Medication}

Among patients with data at month $6(n=64)$, mean (SD) TSQM-9 scores were 56.8 (25.4) for 


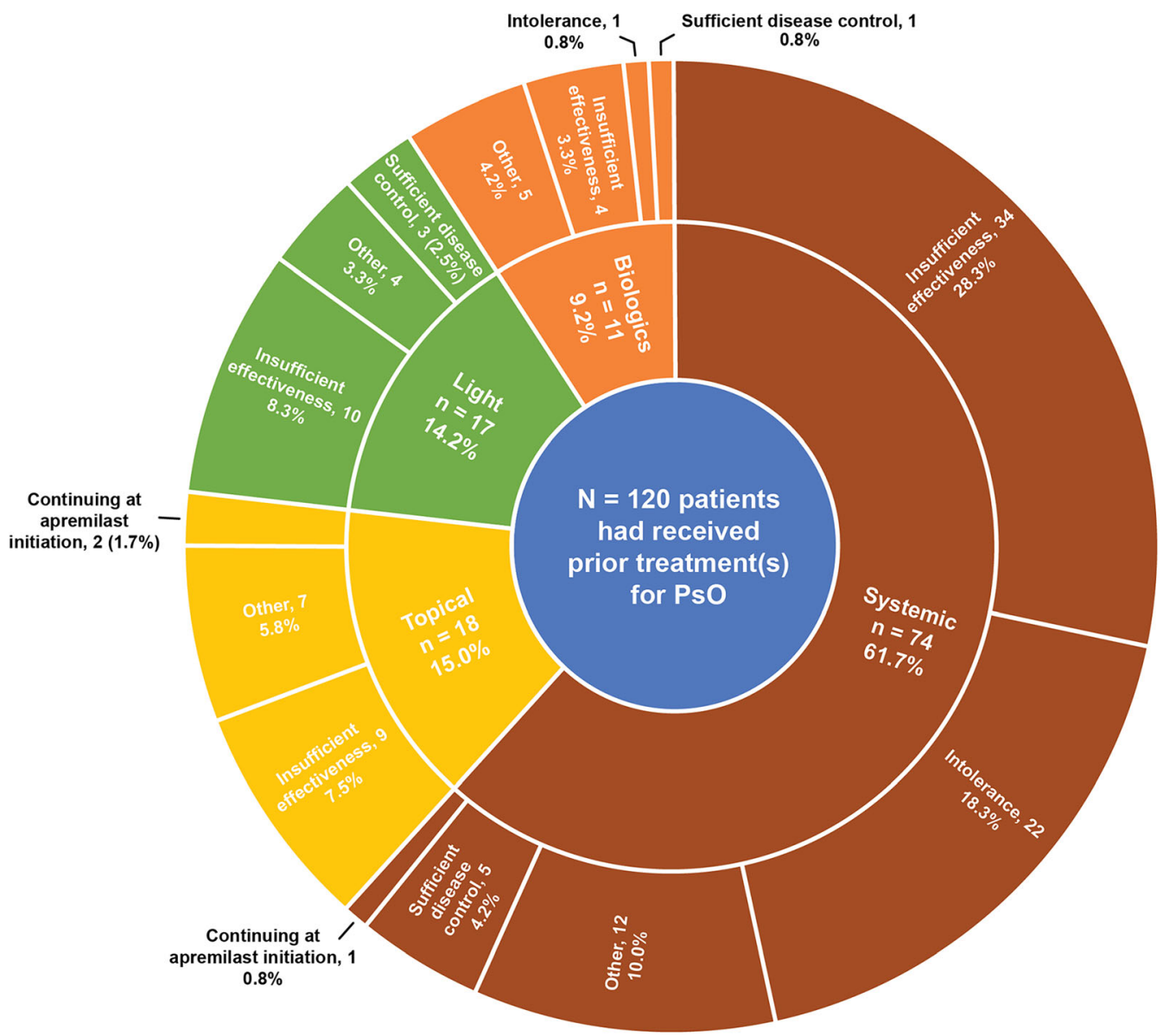

Fig. 1 Last psoriasis treatment before apremilast initiation and reasons for discontinuation (safety analysis set). PsO psoriasis

effectiveness, 75.9 (21.0) for convenience, and 54.7 (29.0) for global satisfaction.

\section{Patient Global Assessment}

At apremilast initiation, over half of all patients with available data assessed their disease as "severe" (45/84 [53.6\%]). At month 6, the majority of patients assessed their disease as "very mild" or "mild" (15/64 [23.4\%] and 19/64 [29.7\%]), and only $12.5 \%(8 / 64)$ assessed their disease as "severe" (Fig. 4).

\section{Disease Activity Scores}

PASI scores are summarised in Table 2. At apremilast initiation, mean (SD) PASI was 13.6
(6.8) and only one patient had a PASI score of 3 or less. Among patients with data at months 3 and 6, mean (SD) scores were 6.4 (6.5) and 6.8 (7.3), respectively, and $34.8 \%$ and $37.1 \%$ had a PASI score of 3 or less, respectively (Table 2 ). Most patients achieved a reduction of at least $50 \%$ (PASI 50) at months 3 and $6(71.9 \%$ and $68.4 \%$, respectively); $29.7 \%$ and $35.1 \%$ achieved at least a 75\% reduction (PASI 75) at months 3 and 6 , respectively.

BSA scores are summarised in Table 3. Mean (SD) BSA scores decreased from $14.5 \%$ (9.2) at apremilast initiation to $8.6 \%$ (10.7) and $8.7 \%$ (10.7) at months 3 and 6, respectively. The percentage of patients with a BSA score of at least $10 \%$ decreased from $84.9 \%$ at baseline to $27.3 \%$ and $32.1 \%$ at months 3 and 6 , respectively. 


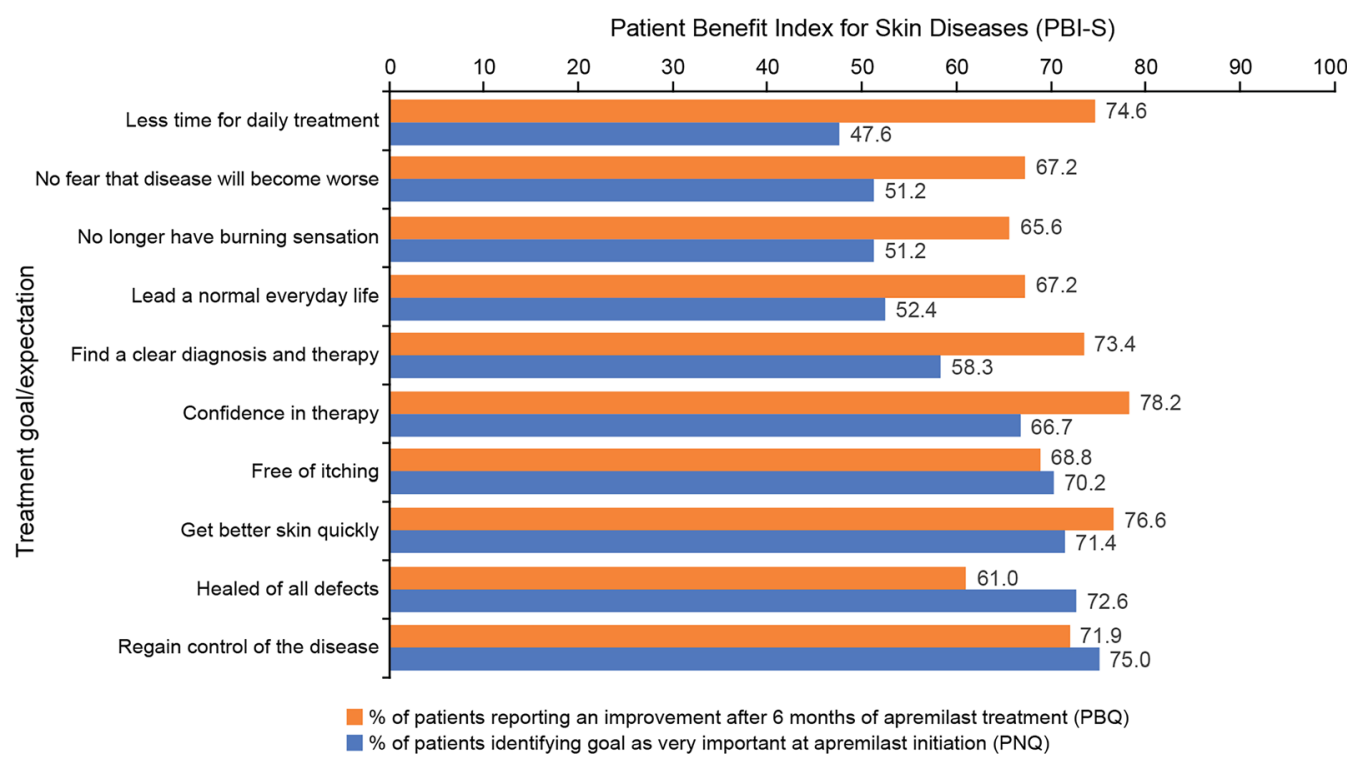

Fig. 2 Patient Benefit Index for Skin Diseases (REF): the 10 treatment goals most commonly identified as "very important" at apremilast initiation (PNQ) and the percentage of patients reporting benefit on these goals at
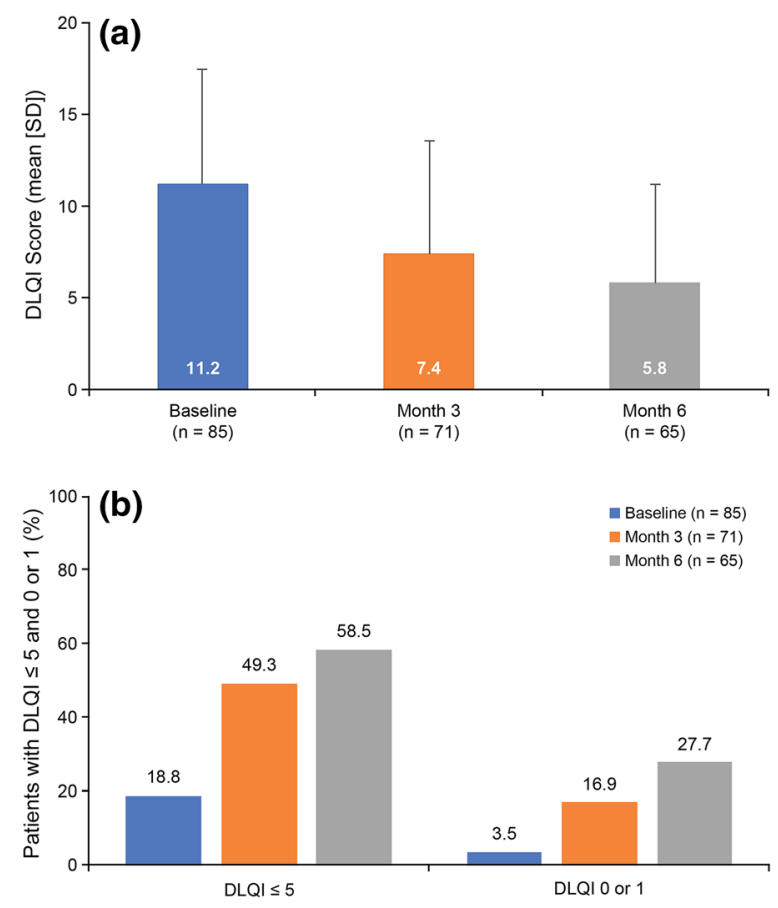

Fig. 3 DLQI at apremilast initiation and months 3 and 6. a Mean scores. b Percentage of patients with score $\leq 5$ and score 0 or 1 (REF). DLQI Dermatology Life Quality Index, REF reference analysis set month 6 (PBQ). Data are expressed as percentages. PBQ Patient Benefit Questionnaire, PNQ Patient Needs Questionnaire, REF reference analysis set

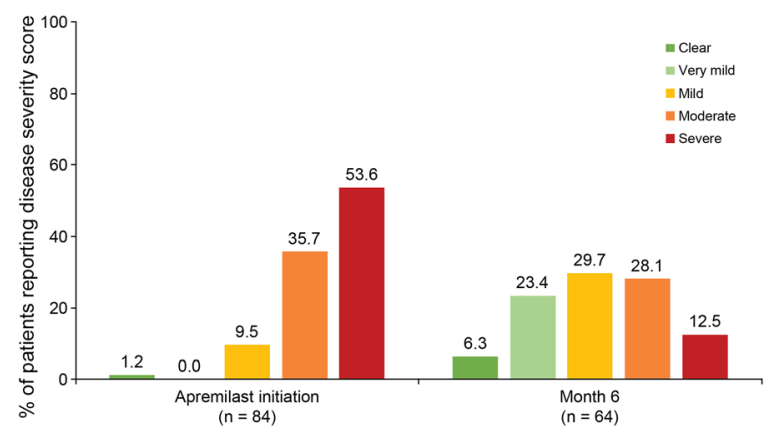

Fig. 4 PtGA scores at apremilast initiation and months 3 and 6 (REF). PtGA Patient Global Assessment, REF reference analysis set

\section{Safety}

A total of $51(41.8 \%)$ patients in the SAF $(N=122)$ reported at least one treatment-related TEAE, the most frequently reported being gastrointestinal disorders $(36 / 122 \quad$ [29.5\%] patients; specifically, diarrhoea, 26 [21.3\%], nausea 11 [9.0\%]), followed by nervous system disorders (11 [9.0\%] patients), psychiatric disorders (10 [8.2\%] patients), general disorders and administrative site conditions (9 [7.4\%] 
Table 2 PASI scores at apremilast initiation and months 3 and 6 (REF)

\begin{tabular}{lll}
\hline REF $(N=89)$ & & \\
\cline { 2 - 3 } $\begin{array}{l}\text { Apremilast } \\
\text { initiation }\end{array}$ & Month 3 & Month 6 \\
\hline
\end{tabular}

\section{PASI}

$\begin{array}{ll}n & 83 \\ \text { Mean } & 13.6(6.8)\end{array}$

(SD)

$$
\text { 95\% CI } 12.1-15.0
$$

Change from baseline

$\begin{array}{ll}n & \text { NA } \\ \text { Mean } & \end{array}$

(SD)

Patients achieving PASI $\leq 3$

$\begin{array}{llll}n & 83 & 69 & 62 \\ \text { No, } n(\%) & 82(98.8) & 45(65.2) & 39(62.9) \\ \begin{array}{l}\text { Yes, } \\ n(\%)\end{array} & 1(1.2) & 24(34.8) & 23(37.1)\end{array}$

Patients achieving PASI 50

$$
\begin{array}{llll}
n & 64 & 57 \\
\text { No, } n(\%) & \text { NA } & 18(28.1) & 18(31.6) \\
\text { Yes, } & 46(71.9) & 39(68.4) \\
n(\%) & &
\end{array}
$$

Patients achieving PASI 75

$\begin{array}{llll}n & 64 & 57 \\ \text { No, } n(\%) & \text { NA } & 45(70.3) & 37(64.9) \\ \text { Yes, } & 19(29.7) & 20(35.1) \\ n(\%) & & \end{array}$

$n$ number of patients with available data or number of patients in the relevant category, PASI 50 reduction in PASI score of at least 50\%, PASI 75 reduction in PASI score of at least $75 \%, C I$ confidence interval, $N A$ not applicable, PASI Psoriasis Area and Severity Index, REF reference analysis set, $S D$ standard deviation

patients), skin and subcutaneous tissue disor-

\begin{tabular}{|c|c|c|c|}
\hline & \multicolumn{3}{|c|}{$\operatorname{REF}(N=89)$} \\
\hline & $\begin{array}{l}\text { Apremilast } \\
\text { initiation }\end{array}$ & Month 3 & Month 6 \\
\hline \multicolumn{4}{|c|}{ Observed values } \\
\hline$n$ & 73 & 66 & 56 \\
\hline $\begin{array}{r}\text { Mean } \\
(\mathrm{SD})\end{array}$ & $14.5(9.2)$ & $8.6(10.7)$ & $8.7(10.7)$ \\
\hline $95 \% \mathrm{CI}$ & $12.3-16.6$ & $6.0-11.3$ & $5.8-11.5$ \\
\hline \multicolumn{4}{|c|}{ Change from baseline } \\
\hline$n$ & & 58 & 50 \\
\hline $\begin{array}{r}\text { Mean } \\
(\mathrm{SD})\end{array}$ & NA & $\begin{array}{r}-7.2 \\
(8.4)\end{array}$ & $\begin{array}{r}-6.8 \\
(8.5)\end{array}$ \\
\hline \multicolumn{4}{|c|}{ BSA scores, $n(\%)$} \\
\hline$<3 \%$ & $1(1.4)$ & $18(27.3)$ & $17(30.4)$ \\
\hline $3-10 \%$ & $10(13.7)$ & $30(45.5)$ & $21(37.5)$ \\
\hline$\geq 10 \%$ & $62(84.9)$ & $18(27.3)$ & $18(32.1)$ \\
\hline
\end{tabular}
ders (6 [4.9\%] patients), weight loss (4 [3.3\%] patients) and musculoskeletal and connective
Table 3 BSA values at apremilast initiation and months 3 and 6 (REF)

$n$ number of patients with available data or number of patients in the relevant category, $B S A$ body surface area, $C I$ confidence interval, $N A$ not applicable, $R E F$ reference analysis set, $S D$ standard deviation

tissue disorders (3 [2.5\%] patients; Table 4). The majority of the treatment-related events of diarrhoea and headache occurred in the 6 days before or 1 week after apremilast initiation (diarrhoea, 13/26 [50.0\%] and 9/26 [34.6\%], respectively; headache, $1 / 9$ [11.1\%] and 5/9 [55.6\%], respectively). The majority of treatment-related TEAEs were assessed as mild or moderate, except for erythema and facial oedema (1 [0.8\%] patient, each), two events of diarrhoea (2 [1.6\%]), one event of gastritis and one of nausea (1 [0.8\%] each) which were assessed as severe. Most of these events led to apremilast discontinuation or withdrawal; the event of gastritis led to a dose reduction and dose was not modified for one event of diarrhoea. Two psychiatric disorder events, depression and suicidal ideation (1 [0.8\%] patient each), were assessed as serious and severe, and led to apremilast withdrawal. 
Table 4 Treatment-related TEAEs observed in more than $2 \%$ of patients (SAF)

\begin{tabular}{|c|c|}
\hline & $\begin{array}{l}\text { SAF } \\
(N=122)\end{array}$ \\
\hline $\begin{array}{l}\text { Patients with at least one treatment-related } \\
\text { TEAE, } \mathrm{n}(\%)\end{array}$ & $51(41.8)$ \\
\hline \multicolumn{2}{|l|}{ SOC } \\
\hline PT & \\
\hline Gastrointestinal disorders, $n$ (\%) & $36(29.5)$ \\
\hline Diarrhoea & $26(21.3)$ \\
\hline Nausea & $11(9.0)$ \\
\hline Nervous system disorders, $n(\%)$ & $11(9.0)$ \\
\hline Headache & $9(7.4)$ \\
\hline Psychiatric disorders, $n(\%)$ & $10(8.2)$ \\
\hline Insomnia & $5(4.1)$ \\
\hline $\begin{array}{l}\text { General disorders and administration site } \\
\text { conditions, } n(\%)\end{array}$ & $9(7.4)$ \\
\hline Fatigue & $5(4.1)$ \\
\hline $\begin{array}{l}\text { Skin and subcutaneous tissue disorders, } \\
n(\%)\end{array}$ & $6(4.9)$ \\
\hline Investigations, $n$ (\%) & $4(3.3)$ \\
\hline Weight decreased & $4(3.3)$ \\
\hline $\begin{array}{l}\text { Musculoskeletal and connective tissue } \\
\text { disorders, } n(\%)\end{array}$ & $3(2.5)$ \\
\hline
\end{tabular}

TEAEs were defined as adverse event that started or worsened within 6 days before the first dose of apremilast and up to 30 days after the last dose

$P T$ preferred term, $S A F$ safety analysis set, SOC System Organ Class, TEAE treatment-emergent adverse event

Other serious TEAEs observed during the study but assessed as not related to apremilast were erysipelas, septic shock (resulting in death), urinary tract infection, unstable angina, head injury and diabetes mellitus (reported for 1 [0.8\%] patient each).

\section{DISCUSSION}

Data regarding the effectiveness and tolerability of apremilast for the treatment of moderate to severe plaque psoriasis in clinical practice are limited. The OTELO study was designed to assess this from the perspectives of both the patient and the treating dermatologist.

In clinical trials, efficacy is typically assessed by the physician, using clinical scores or questionnaires, which provide a general clinical impression. PASI is the most frequently used score to assess the efficacy of psoriasis treatment over time [24-26] and is part of the eligibility criteria for apremilast reimbursement in Belgium. However, several studies on skin disease suggest the physicians' and patients' assessments of the effectiveness of treatment can differ markedly and that patients themselves are more reliable in assessing treatment benefits [27]. The PBI-S was developed to evaluate patient-defined benefits of dermatological therapies [14-17]. We used the PBI-S as the primary outcome in our study to evaluate the patient's perception of the effectiveness of apremilast after 6 months of treatment. To complement the PBI-S, we evaluated patient QoL using the DLQI questionnaire, patient treatment satisfaction using the TSQM-9 questionnaire and patient-reported disease severity using the PtGA questionnaire.

The PBI-S questionnaire identified a clear trend in patients' treatment expectations, with the majority of patients identifying items relating to physical impairments as the most important. The benefits of apremilast treatment were apparent at 6 months, with more than half of patients reporting satisfactory progress against these expectations. The DLQI, TSQM-9 and PtGA scores showed a similar trend, with patients reporting improvement in their QoL and disease severity, and satisfaction with apremilast treatment. From a patient's perspective, these results indicate that use of apremilast for the treatment of psoriasis was linked to improvement in all QoL indicators assessed in this study, with a reduction in the physical, social and psychological impacts of the disease. These findings were also reflected in the PASI and BSA scores, which assess disease symptoms from the physician's perspective. A reduction in PASI was seen after 3 months of apremilast treatment and was maintained after 6 months. Correspondingly, the number of patients 
achieving PASI 50 and PASI 75 increased on apremilast treatment.

Our results for the PASI scores are consistent with those observed in the phase III ESTEEM 1 and 2 and in the phase IIIb LIBERATE studies $[11,12,28,29]$. In these studies, the percentage of patients achieving PASI 75 at 4 months after treatment initiation was $28.8 \%$ (ESTEEM 2 ) and $39.8 \%$ (LIBERATE), similar to the $29.7 \%$ we observed at month 3. Furthermore, our results for PBI-S are in line with interim results from the observational APPRECIATE study [30], in which the majority of patients (76-84\%, depending on the item) reported an improvement of the identified primary needs after 6 months of treatment with apremilast.

Diarrhoea, nausea, and headache were the most common treatment-related adverse events reported in our study. Most treatment-related events of diarrhoea and headache occurred in the 6 days prior to or the week after apremilast initiation. Most of these AEs were mild in severity and generally resolved within 1 month, which was in line with previous studies on apremilast [11, 12, 28]. Overall, the TEAEs observed in the OTELO study were aligned with the known safety profile of apremilast [10]; most treatment-related adverse events were mild or moderate and no new safety signals were observed.

The key strength of OTELO is that it provides insights into the impact of apremilast treatment among patients with moderate to severe psoriasis in a real-world setting. However, the following limitations should be considered while interpreting the findings of this observational study: the sample size was small, especially after month 9 as a result of study termination; the percentage of missing data increased over time (with data missing for approximately $50 \%$ of patients by month 3); the study focused on patient-reported outcomes (PBI-S, DLQI, TSQM9 and PtGA) and few clinical outcome measures were assessed; while the patients' evaluation of their disease progression is becoming ever more significant in clinical trials, they are subjective and most likely lead to large inter-individual variability in the observed data. Therefore, the data should be interpreted with caution.

\section{CONCLUSIONS}

Our data demonstrate the real-life effectiveness and tolerability of apremilast for the treatment of moderate to severe plaque psoriasis in Belgian clinical practice. Apremilast improved quality of life, disease activity measures, patient benefits and treatment satisfaction, and was well tolerated with no new safety signals.

\section{ACKNOWLEDGEMENTS}

We thank all the patients who participated in the OTELO study, as well as the investigators from each study centre and their collaborators.

Funding. This study was funded by Celgene. Amgen acquired the worldwide rights to Otezla $^{\circledR}$ (apremilast) on November 21, 2019. Amgen funded the journal's rapid service and open access fees.

Medical Writing and Editorial Assistance. Roberta Farina and Pavlos Alifragkis from Keyrus Life Science, funded by Amgen, provided support for data management, statistical analysis, the writing of OTELO protocol and study report and medical writing support for this manuscript. Claire Desborough, an Amgen employee, provided editorial support for this manuscript.

Authorship. All named authors meet the International Committee of Medical Journal Editors (ICMJE) criteria for authorship for this article, take responsibility for the integrity of the work as a whole, and have given their approval for this version to be published.

Author Contributions. Conceptualization: Jo Lambert, Michel de la Brassinne, Pierre-Dominique Ghislain, and Siegfried Segaert. Methodology: Jo Lambert, Michel de la Brassinne, Pierre-Dominique Ghislain, and Siegfried Segaert. Formal analysis and investigation: Jo Lambert, Michel de la Brassinne, Pierre-Dominique Ghislain, Pierre-Paul Roquet-Gravy, Siegfried Segaert, Tom Hillary, Xuãn-Lan Lam 
Hoai. Writing-review and editing: Jo Lambert, Michel de la Brassinne, Pierre-Dominique Ghislain, Pierre-Paul Roquet-Gravy, Siegfried Segaert, Tom Hillary, Xuãn-Lan Lam Hoai.

Disclosures. Dr. Pierre-Dominique Ghislain has received speaker and investigator fees or grants from AbbVie, Almirall, Amgen, BMS, Eli Lilly, Flen, Galderma, Janssen, LEO Pharma, Maruho, Meda, Menarini, MSD, Novartis, PellePharm, Pfizer, Serono, UCB and Viatris. Dr. Tom Hillary received grants or fees for consultancy, speaker fees, support for travel from AbbVie, Almirall, Amgen, Biogen, Celgene, Janssen, Leo, Eli Lilly, Novartis, Pfizer, Roche, Sandoz, Sanofi and UCB. Dr. Pierre-Paul RoquetGravy has been an investigator, speaker, advisory board member, and consultant for AbbVie, Bioderma, Boehringer Ingelheim, Galderma, GSK, Janssen, LEO Pharma, Merck, MSD, Novartis, Pfizer, Regeneron Pharmaceuticals and Sanofi Genzyme. Prof. Dr. Michel de la Brassinne has received lecture and/or consultation fees and/or travel reimbursement from AbbVie, Almirall, Amgen, Celgene, Eli Lilly, Galderma, Janssen, LEO Pharma, Novartis, Pfizer, UCB and Viatris. Prof. Dr. Siegfried Segaert has received speaker or consultation fees from AbbVie, Almirall, Amgen, Biogen, Boehringer Ingelheim, Celgene, Eli Lilly, Galderma, Glenmark, Janssen, LEO Pharma, Merck Serono, MSD, Novartis, Pierre Fabre, Pfizer, Roche, Sun Pharma and UCB. Prof. Dr. Jo Lambert and Dr. Xuãn-Lan Lam Hoai have no conflicts to disclose.

Compliance with Ethical Guidelines. The study protocol was approved by the medical ethics committee of UZ Leuven and was conducted in accordance with the International Council for Harmonisation of Technical Requirements for Pharmaceuticals for Human Use Guideline for Good Clinical Practice, the guiding principles of the Declaration of Helsinki 1964, and its later amendments. Informed consent was obtained from all the subjects participating in this study.

Data Availability. The datasets generated during and/or analysed during the current study are available from the corresponding author on reasonable request. Qualified researchers may request data from Amgen clinical studies. Complete details are available at the following: https://www.amgen.com/science/ clinical-trials/clinical-data-transparency-practices/ clinical-trial-data-sharing-request.

Open Access. This article is licensed under a Creative Commons Attribution-NonCommercial 4.0 International License, which permits any non-commercial use, sharing, adaptation, distribution and reproduction in any medium or format, as long as you give appropriate credit to the original author(s) and the source, provide a link to the Creative Commons licence, and indicate if changes were made. The images or other third party material in this article are included in the article's Creative Commons licence, unless indicated otherwise in a credit line to the material. If material is not included in the article's Creative Commons licence and your intended use is not permitted by statutory regulation or exceeds the permitted use, you will need to obtain permission directly from the copyright holder. To view a copy of this licence, visit http://creativecommons.org/licenses/by$\mathrm{nc} / 4.0 /$.

\section{REFERENCES}

1. World Health Organization. Global report on psoriasis. Geneva: World Health Organization; 2016.

2. European Medicines Agency. Guideline on clinical investigation of medicinal products indicated for the treatment of psoriasis. 2009. http://www.ema. europa.eu/docs/en_GB/document_library/Scientif ic_guideline/2009/09/WC500003329.pdf. Accessed July 2020.

3. Augustin M, Reich K, Glaeske G, Schaefer I, Radtke M. Co-morbidity and age-related prevalence of psoriasis: analysis of health insurance data in Germany. Acta Derm Venereol. 2010;90(2):147-51.

4. Ferrándiz C, Bordas X, García-Patos V, Puig S, Pujol $\mathrm{R}$, Smandía A. Prevalence of psoriasis in Spain (epiderma project: phase I). J Eur Acad Dermatol Venereol. 2001;15(1):20-3. 
5. Hawkes JE, Chan TC, Krueger JG. Psoriasis pathogenesis and the development of novel targeted immune therapies. J Allergy Clin Immunol. 2017;140(3):645-53.

6. Stern RS, Nijsten T, Feldman SR, Margolis DJ, Rolstad T. Psoriasis is common, carries a substantial burden even when not extensive, and is associated with widespread treatment dissatisfaction. J Investig Dermatol Symp Proc. 2004;9(2):136-9.

7. Cai Y, Fleming C, Yan J. New insights of T cells in the pathogenesis of psoriasis. Cell Mol Immunol. 2012;9(4):302-9.

8. Schafer P. Apremilast mechanism of action and application to psoriasis and psoriatic arthritis. Biochem Pharmacol. 2012;83(12):1583-90.

9. Otezla. 2021. Summary of product characteristics. https://www.ema.europa.eu/en/documents/productinformation/otezla-epar-product-information_en.pdf. Accessed Aug 2021.

10. European Medicines Agency. 2020. European public assessment report (EPAR) for Otezla. https://www. ema.europa.eu/en/medicines/human/EPAR/otezla. Accessed Jul 2020.

11. Papp K, Reich K, Leonardi CL, et al. Apremilast, an oral phosphodiesterase 4 (PDE4) inhibitor, in patients with moderate to severe plaque psoriasis: results of a phase III, randomized, controlled trial (efficacy and safety trial evaluating the effects of apremilast in psoriasis [ESTEEM] 1). J Am Acad Dermatol. 2015;73(1):37-49.

12. Paul C, Cather J, Gooderham M, et al. Efficacy and safety of apremilast, an oral phosphodiesterase 4 inhibitor, in patients with moderate-to-severe plaque psoriasis over 52 weeks: a phase III, randomized controlled trial (ESTEEM 2). Br J Dermatol. 2015;173(6):1387-99.

13. The reimbursement criteria for Otezla in psoriasis in Belgium. 2021. https://ondpanon.riziv.fgov.be/ SSPWebApplicationPublic/fr/Public/ProductSearch. Accessed Aug 2021.

14. Augustin M, Radtke MA, Zschocke I, et al. The patient benefit index: a novel approach in patientdefined outcomes measurement for skin diseases. Arch Dermatol Res. 2009;301(8):561-71.

15. Augustin M, Reich C, Schaefer I, Zschocke I, Rustenbach SJ. Development and validation of a new instrument for the assessment of patient-defined benefit in the treatment of acne. J Dtsch Dermatol Ges. 2008;6(2):113-20.

16. Augustin M, Spehr C, Radtke MA, et al. German psoriasis registry PsoBest: objectives, methodology and baseline data. J Dtsch Dermatol Ges. 2014;12(1):48-57.

17. Feuerhahn J, Blome C, Radtke M, Augustin M. Validation of the patient benefit index for the assessment of patient-relevant benefit in the treatment of psoriasis. Arch Dermatol Res. 2012;304(6): 433-41.

18. Feldman SR, Krueger GG. Psoriasis assessment tools in clinical trials. Ann Rheum Dis. 2005;64(Suppl 2): ii65-68.

19. Mease PJ, Menter MA. Quality-of-life issues in psoriasis and psoriatic arthritis: outcome measures and therapies from a dermatological perspective. J Am Acad Dermatol. 2006;54(4):685-704.

20. Atkinson MJ, Kumar R, Cappelleri JC, Hass SL. Hierarchical construct validity of the treatment satisfaction questionnaire for medication (TSQM version II) among outpatient pharmacy consumers. Value Health. 2005;8(Suppl 1):S9-2419.

21. Bharmal M, Payne K, Atkinson MJ, Desrosiers M-P, Morisky DE, Gemmen E. Validation of an abbreviated Treatment Satisfaction Questionnaire for Medication (TSQM-9) among patients on antihypertensive medications. Health Qual Life Outcomes. 2009;7:36.

22. Mamolo C, Harness J, Tan H, Menter A. Tofacitinib (CP-690,550), an oral Janus kinase inhibitor, improves patient-reported outcomes in a phase $2 \mathrm{~b}$, randomized, double-blind, placebo-controlled study in patients with moderate-to-severe psoriasis. J Eur Acad Dermatol Venereol. 2014;28(2):192-203.

23. Valenzuela F, Paul C, Mallbris L, et al. Tofacitinib versus etanercept or placebo in patients with moderate to severe chronic plaque psoriasis: patient-reported outcomes from a phase 3 study. J Eur Acad Dermatol Venereol. 2016;30(10):1753-9.

24. Mrowietz U, Kragballe K, Reich K, et al. Definition of treatment goals for moderate to severe psoriasis: a European consensus. Arch Dermatol Res. 2011;303(1):1-10.

25. Naldi L, Rzany B. Psoriasis (chronic plaque). BMJ Clin Evid. 2009;2009:1706.

26. National Clinical Guideline Centre. National Institute for Health and Clinical Excellence: Guidance. In: Psoriasis: Assessment and management of psoriasis. London: Royal College of Physicians; 2012.

27. van de Kerkhof PCM, Reich K, Kavanaugh A, et al. Physician perspectives in the management of psoriasis and psoriatic arthritis: results from the population-based Multinational Assessment of Psoriasis 
and Psoriatic Arthritis survey. J Eur Acad Dermatol Venereol. 2015;29(10):2002-10.

28. Reich K, Gooderham M, Green L, et al. The efficacy and safety of apremilast, etanercept and placebo in patients with moderate-to-severe plaque psoriasis: 52-week results from a phase IIIb, randomized, placebo-controlled trial (LIBERATE). J Eur Acad Dermatol Venereol. 2017;31(3):507-17.

29. Reich K, Soung J, Gooderham M, Zhang Z, Nograles $\mathrm{K}$, Goodfield M. LIBERATE trial: sustained efficacy of apremilast in patients with moderate-to-severe psoriasis who continued on apremilast or switched from etanercept treatment. $\mathrm{Br} \mathrm{J}$ Dermatol. 2016;175:71-2.

30. Shams K, Laws P, Chen KS, et al. Patient-reported insights from the APPRECIATE study: real-world experience of psoriasis patients treated with apremilast in the UK and Ireland. In: British Association of Dermatologists 98th annual meeting. J Dermatol 2018;179(Suppl 1):3-211. 